\title{
Offsite Construction in the UK Housing Sector: Barriers and Challenges
}

\author{
Peter KILLIAN ${ }^{1}$, Prof Mohammed ARIF ${ }^{2}$, Dr. Gerrard WOOD ${ }^{3}$, Amit KAUSHIK ${ }^{3 *}$ \\ ${ }^{1}$ Knowledge Transfer Partnership Associate, University of Salford and Manchester city council \\ ${ }^{2}$ Professor, School of Built Environment, University of Salford, UK \\ ${ }^{3}$ Senior Lecturer, School of Built Environment, University of Salford, UK \\ ${ }^{4}$ Research Assistant, School of Built Environment, University of Salford, UK \\ *Corresponding author's e-mail:a.k.kaushik1@salford.ac.uk
}

\begin{abstract}
Offsite construction (OSC) has been presented by researchers and practitioners all over the world as an efficient and effective way of delivering buildings. The benefits regarding time, cost and quality are well-documented. However, it has not been successfully implemented in housing, especially in the affordable housing sector. This paper uses the case study method from the affordable housing sector to document these challenges and proposes a way forward for the sector. Also, findings indicate that the high cost of production was identified as a major barrier to the proliferation of off-site housing in the UK. However, the research found that the effective implementation of processes and practices such as Design for Manufacture and Assembly (DFMA) could reduce the likelihood of cost escalation.
\end{abstract}

\section{KEYWORDS}

Modular and Offsite construction; UK Housing sector; Barriers; Challenges

\section{INTRODUCTION}

UK's housing shortfall has triggered a re-evaluation of the nation's approach to building. The Construction Industry Council's Off-site Housing Review (Miles \& Whitehouse, 2013) and The Lyons Review (Lyons, 2014) suggest that OSC technologies should be harnessed to facilitate increases in the supply of affordable homes. However, despite the potential of off-site, the UK's attitude towards innovation in home building is relatively conservative compared to other developed economies (Nadim and Goulding, 2010). For example, the majority of houses in the UK are still constructed with brick and concrete block walls because house builders have been slow to adopt modern methods of construction. Numerous studies have attempted to examine industry approaches to off-site building methods. Edge et al. (2002) found that potential home buyers hold negative perceptions of post-war prefabricated homes and often resist any products that do not resemble a traditional house. This perception barrier can also exist among architects and designers. While perceptions are important, Venables et al. (2004) suggest that the views of developers partly influence off-site manufacture and partly by wider market and regulatory factors. Technical difficulties such as site planning, logistics, and a fragmented supply chain can also inhibit the acceptance of OSC among industry professionals (Pan, Gibb \& Dainty, 2007). These implementation issues were the focus of a 2012 study for the International Council for Research and Innovation in Building and Construction (CIB). A team of leading Off-site academics led a series of workshops with housing industry practitioners who identified that off- 
site building represents a new paradigm, and therefore different approaches to 'design, manufacture, and construction' are required to achieve optimal outcomes (Arif, Rahimian, \& Goulding, 2012). Also, a previous study by Goodier and Gibb (2007) found that the additional cost of OSC compared to traditional construction severely restricts UK off-site housing developments. Therefore, barriers relating to cost, perception, and implementation may be inhibiting the growth of OSC as modern methods of construction are not yet a significant feature of the UK homes market. The purpose of this paper is to look at offsite and present lessons learnt from two case studies of implementation of offsite construction in the housing sector. The rest of the paper has four more sections. The next section presents an overview of offsite construction. It is followed by a section on research methodology and finally the case study is presented. The last section discusses the conclusions of this paper.

\section{OFF-SITE CONSTRUCTION}

The use of prefabrication techniques in the UK can be traced back to the Industrial Revolution: London's Crystal Palace, built in 1851, is one well-known early example of OSC. Off-site can also be rapidly deployed to meet the needs of growing demand and resource scarcity. OSC harnesses practices from the manufacturing sector; this has included utilizing the advantages of the assembly line and mass production. The resulting benefits are often improvements in quality and productivity. Over the last twenty years, numerous state-funded reports have called for efficiency gains in the UK construction industry, including the government's Construction 2025 Paper (HM Government, 2014), which continues the themes discussed in the frequently cited Egan (1998) and Latham (1994) reports. OSC could potentially be used to tackle many of the shortcomings of the British construction sector. A study by McGraw-Hill Construction across a range of disciplines found that off-site can reduce defects, shorten delivery times, and provide a safer, more environmentally friendly mode of building (McGraw-Hill 2011). In summary, it is clear that off-site can offer many tangible benefits to clients. There are a series of options available when implementing off-site: for instance, panellist, volumetric, hybrid, and manufactured components. The hybrid methodology is commonly employed during the construction of multi-storey developments in the form of a prefabricated concrete building core. It can significantly speed up the construction process. However, research conducted by McKinsey (2015), highlighted that this method could not be used to deliver the full advantages of OSC as it does not represent a fully industrialised approach to building. For a complete manufactured solution, constructors can turn to the volumetric method: the assembly of threedimensional modules within a factory, which are then delivered to the site. In a similar fashion, panelled building constitutes the production of separate sheets in a controlled environment that are assembled on-site to build a three-dimensional structure.

Despite the findings above, a chart developed by the UK National Audit Office (NAO, 2005) using data supplied by the University of Salford. It highlights that the volumetric approach is advantageous regarding speed (Figure 1). For landlords such as housing associations, the shorter build duration of a volumetric scheme could enable the early receipt of rental income, or be utilised to deliver urgently needed housing. Furthermore, a recent study has shown that in addition to compressing time spent on site, housing developers in the UK have reported significant reductions in building defects through the use of off-site methods. Figure 2 presents a summary of the primary improvements off-site can deliver over conventional construction and the resulting benefits to the house builders and clients. 


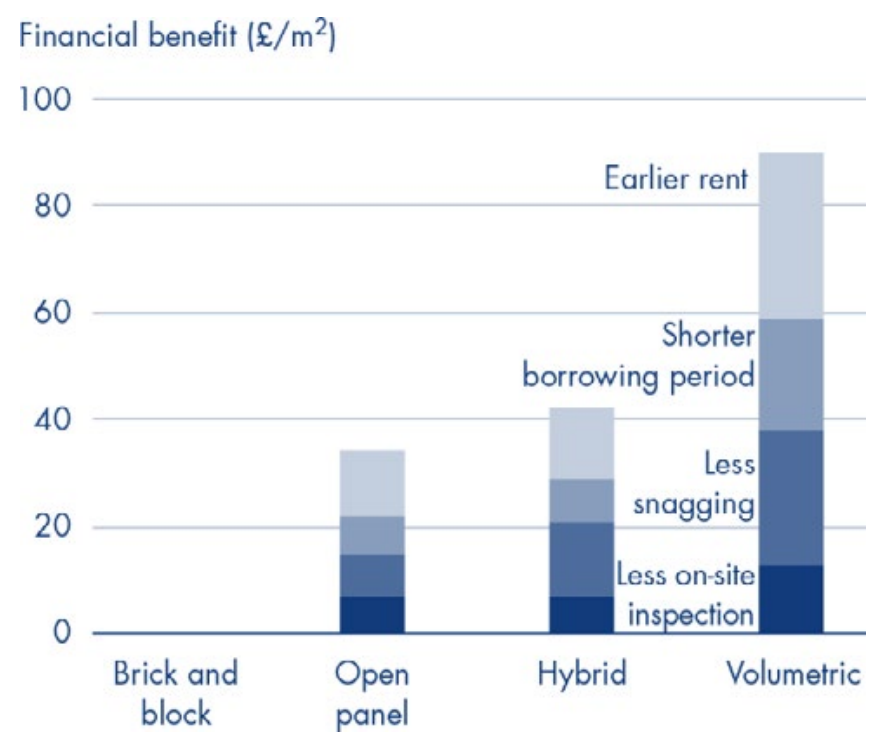

Figure 1 Economic advantage of off-site methods over traditional construction (NAO, 2005)

\begin{tabular}{llll}
\hline Issue & $\begin{array}{l}\text { Improvement Over } \\
\text { Conventional } \\
\text { Construction } \\
\text { (Estimated) }\end{array}$ & Benefit to society & $\begin{array}{l}\text { Benefit to house } \\
\text { builder }\end{array}$ \\
\hline Faster Construction & $\begin{array}{l}\text { Up to } 80 \% \text { time } \\
\text { compression on site }\end{array}$ & Significant & $\begin{array}{l}\text { Large (reduced } \\
\text { construction financing } \\
\text { costs) }\end{array}$ \\
Fewer Defects & Up to 80\% & Small & Significant
\end{tabular}

Table 1 Summary of the benefits of off-site for clients (Miles \& Whitehouse, 2013)

The advantages of prefabrication are not restricted to the short term benefit of improved delivery speed. There is evidence to suggest that off-site can be used as a tool to address environmental concerns. The research of Miles and Whitehouse, (2013) found that transferring onsite activities to the factory can reduce material waste by up to $90 \%$. Furthermore, the energy used in site traffic movement can be reduced by up to $70 \%$ because fewer deliveries are required during the construction period. However, arguably their most significant finding is that building lifecycle energy usage can be cut by $20 \%$. These improvements are achieved through improved insulation and a tighter building enclosure. Also, a report by the World Energy Council (2013) estimates that up to $40 \%$ of the cost of a building is incurred through in-house energy consumption and maintenance. Therefore, it is clear that off-site methods can offer substantial environmental benefits over the long term. Building life-cycle energy use is considered a salient issue in the UK. In 2010 when the British Government decided to implement amendments to the national building regulations part L (HM, 2014) to tighten the energy performance criteria for new homes. 
OSC can also address challenges relating to social sustainability. Lu (2009) contends that the increased productivity resulting from controlled and predictable off-site working methods attract investors. In turn, investment in technology implies increased opportunities for training, which can help address the UK's skills gap. A further benefit of implementing OSC is that it can facilitate improved safety standards during a project. A safer working environment can be achieved through the assembly of components in a controlled factory environment. Industrialisation also reduces labour requirements and therefore can restrict site congestion and noise; this can be of significant benefit for client's constructing new housing projects within existing high-density residential estates. Furthermore, the use of modular technology limits activities at elevated levels such as traditional roof building.

A reduction in people working at height can lower the likelihood of hazardous falls, the primary cause of fatalities in the UK construction industry throughout 2013-2014. Therefore, off-site methods can be implemented by clients as part of their health and safety strategies in order support efforts to ensure project risks are kept as low reasonably practicable. Despite these benefits, the uptake of offsite in the housing sector within the UK has been low. To investigate this low uptake, this research will present two case studies and understand the reasons for effective implementation of offsite in the UK. These reasons could be used to formulate a way forward.

\section{RESEARCH METHODS}

To examine current approaches to UK off-site home commissioning, the practices of off-site construction, were applied to two case studies. Yin (2013) defines case research methods as empirical inquiries that investigate subjects in a real-life context, where boundaries are not clearly defined and multiple evidential sources can be analysed. Case studies can be explained as a focus on a small volume of scenarios, as opposed to a large population of samples (Stake, 1980). Because there is a lack of recent samples of affordable UK Off-site scheme, this approach offers a practical solution. Case methodology is also useful for assessing qualitative variables such as perception and motivation, salient qualitative factors in Off-site implementation.

The method of data collection was a semi-structured interview. This approach offers the opportunity to probe for honest and in-depth responses (Gray, 2013). Furthermore, open questions were employed to extract motivations and reasoning behind actions taken. For the purpose of the study, one recent off-site project from three separate housing associations was selected. The organisation chosen specialise in the commissioning of affordable homes and are registered providers of social housing in the UK. They also have charitable status registered in England and Wales with the FSA as Industrial and Provident Societies, and they are regulated by the Homes and Communities Agency. One person from each association was interviewed regarding the projects that we shall name A. A representative of each manufacturer supplying the homes was interviewed to corroborate the views of the clients. All projects reviewed were part self-financed and part-financed by HCA government grants.

The housing association interviews took place at the participant's place of work, and the manufacturer interviews were conducted by telephone. It took between forty minutes to one hour to conduct each meeting. Each interviewee was informed of the significance of the study and that the commissioning of the projects was the unit of analysis. According to Oppenheim (1992), 
prompting can lead to interview bias. The participants were allowed to expand upon their answers without much restriction. Additionally, they were asked to put forward any designs, plans, or photographs documenting the projects. Issues about ethics and safety were given much consideration during the planning and undertaking of this study. The next section presents the case study.

\section{CASE STUDY}

Case A was undertaken by an organisation which is a social landlord with a stock of over 19,000 properties in the Midlands and the North West of England. It specialises in housing development and construction, and it operates a property repair, maintenance, and improvement division. The group employs approximately 1000 people and works in partnership with some external partners to provide its services.

The organisation first explored off-site housing when a prefabricated bungalow they owned needed replacing due to its poor condition. The property was situated on a sloping site within a small residential cul-de-sac. A winding main road, which was narrow in section, provided access to the nearest motorway located at a distance of five miles. The client perceived that selecting a modular solution for this project would cause less disruption to the surrounding residents.

Following the initial project inception, Organisation A was approached by a consortium of firms offering modular homes. The consortium consisted of three companies: a developer, a manufacturer, and an architectural firm. Company A had already worked with the architect on previous housing schemes. However, they were not familiar with the manufacturer and decided to conduct an initial assessment of the company. The management team took a visit to the factory and was impressed by the facility and the pilot house on display. The analysis of pilot house reported that timber used was of higher quality than timber used by Organisation A's projects. The visit also confirmed that the new homes would be covered by a National House Building Council approved warranty.

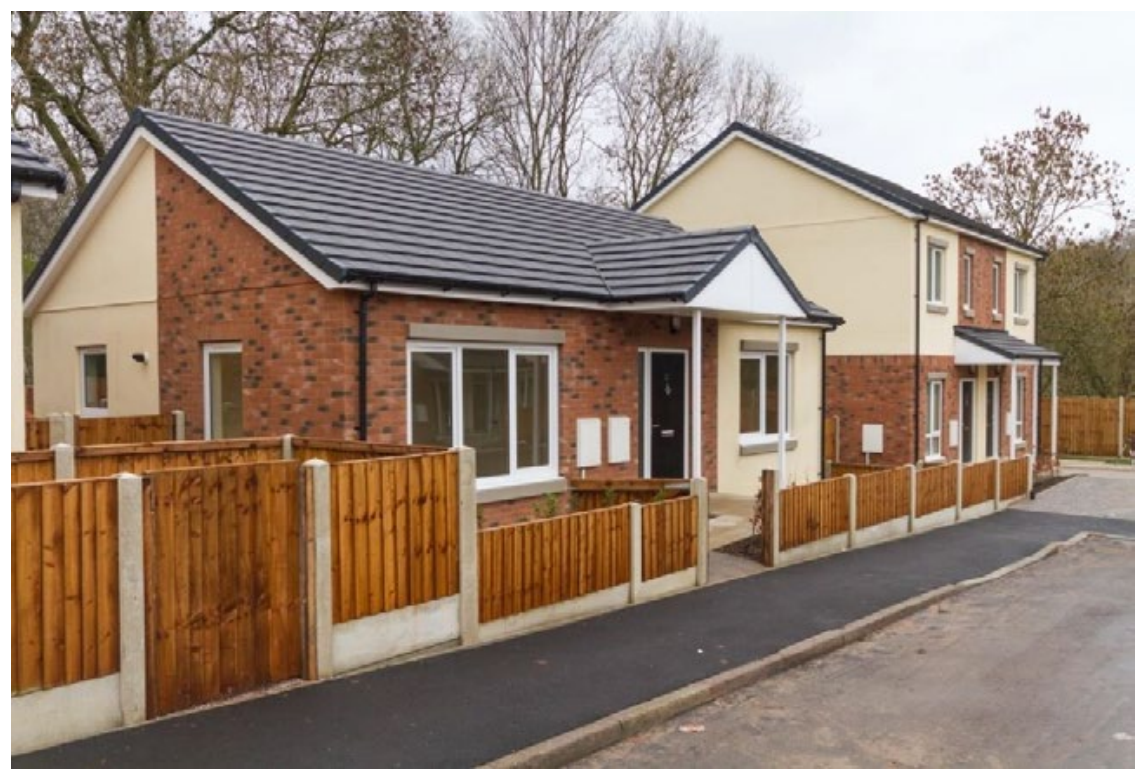

Figure 2 Completed Modular build development 
The architect reported that lack of supply chain accountability would lead to difficulty in arranging the design warranties. The selected architects had a decade of experience in modular school buildings. They were aware that this project required modular design approach (design for manufacture). Despite the architect's experience, there were some design specification issues that were not overcome. The buildings were not designed to allow for water connections to enter the property. Once on site, the water board needed to drill through the property which could have affected the airtightness of the building envelope. The architect used BIM technology and manufacturer used existing software. It lead to some minor difficulties in design information transfer.

A change in ground conditions during the early stages of the scheme led to change from strip foundations to piles foundations. Following completion of the groundwork, the modules were delivered to the site. The manufacturer was responsible for arranging the transportation, assembly, and escorts. Due to space constraints and leveling up delays by assemblers, a decision was taken to unload the house and level them later. All the shipping and assembly was completed within two days and the rate of progress increased on the second day because of the lessons learnt on the first day. In total, the project took the same time as a traditional build, which was longer than expected. However, this extended duration was mainly down to the groundwork changes and the demolition of the existing properties. Additional site issues included a problem with a plastic lining that covered the side of the house. It was expected to easily compress with pressure but it did not and caused a small gap, and therefore some alterations were required. Despite the site issues, the quality of the final product exceeded the client expectations, especially in the area of timber frame quality and insulation. In addition, no health and safety incidents of concern were reported during the construction phase. After the handover, the residents gave positive reports for the new houses and reported no problems. The delays experienced during the construction phase caused the project costs to rise; however, the supply chain absorbed these costs due single price agreement between client and principle contractor. The use of standard design and build form of contract meant that all project deliverables would be completed for the association at a set price, which would only change under a certain set of circumstances. On reflection, much of the risk was passed to the subcontracted main contractor, who then struggled to make the project profitable. This lack of profitability may have caused the subcontractor to reduce expenditure towards the end of the project, similar to traditional construction sector. The financial difficulties and loss on the scheme lead to strained relationships between the supply chain partners. The ineffective coordination of service connections on-site was blamed on the confusion caused by the number of firms in the supply chain. Moreover, the client observed that the principle contractor developer became less active once work started on-site, leaving most of the responsibility with the main building subcontractor, which may explain the difficulties this firm later experienced. However, it was acknowledged that the principle contractor developer played a key role in getting the project off the ground and presenting a viable and attractive offering to the client.

\section{DISCUSSION AND CONCLUSIONS}

One important element for the client analysed in this study is that they decided upon a modular solution in the early stages. The organisation recognised that a fully industrialised approach could introduce greater efficiency to the building process and improve the product quality. One of the key drivers for the organisation to select offsite was the construction skill shortages 
(BIS, 2013). Another reason for using offsite was to minimise the disruption to neighbours, The plot's suitability for modular construction did not seem to play a part in their decision-making. The potential for high speed of delivery was not considered when making the selection of offsite. As social landlords, this could facilitate the early receipt of rental income (a relevant consideration for social landlords). It could either be because these features were judged to be of negligible benefit or that these advantages were not fully appreciated and factored into the proposal. Furthermore, the clients were not significantly influenced by issues of sustainability, which may be considered to be of lower priority, or it could be because they are satisfied that the majority of products on offer meet the required regulatory levels. The study indicates that client may have also overlooked capability assessment. There was no capability assessment of internal staff and client relied on some evidence of off-site knowledge.

The major modular construction benefits realised in the case study are quick delivery speed and less impact on the site. The projects on existing housing estates could benefit a lot from modular construction. It reduces the impact of the development on current residents. Another lesson learnt was to review the supply chain assessments before taking a final decision in the commissioning phase. The client assessed the homer supplier's factory and pilot product. However, the similar assessment was not done focusing architect and subcontractors skill set in modular construction. The early engagement of the design team and focus on DFMA helped to solve some problems at the beginning of the project. Organisation's designers were experienced with off-site projects and took it upon themselves to engage with the manufacturer early in the process. King, Knight, \& Griffith (2001) argue that cohesion between designer and constructor reduce the potential for a lack of coordination within the supply chain. Despite early engagement between designer and manufacturer on the project, not all issues were unavoidable. The success of modular construction relies on the adaptability of complete industrialised process approach and efficient communication between the project partners. This project suffered due to the halfhearted adoption of modular methods and limited communication between delivery partners. This project experience highlights the importance of assessing the supply chain's capability and experience in modular and offsite construction. It is still a relatively new approach, and building sector is still adapting to the new techniques and processes. There are numerous benefits of modular construction but can only be realised if it is implemented with a capable team with modular construction knowledge, a fully industrialised and integrated process from the beginning along with client's leadership in modular construction adoption. The future studies on offsite construction in the housing sector can be focused on analysing the degree of adoption of industrialised process in the of modular construction projects.

\section{ACKNOWLEDGEMENT}

This research is supported by Innovate UK and Manchester City Council under the Knowledge Transfer Partnership project (KTP009892) in collaboration with University of Salford.

\section{REFERENCES}

Arif, M., Goulding, J., \& Rahimian, F. P. (2012). Promoting offsite construction: Future challenges and opportunities. Journal of Architectural Engineering, 18(2), 75-78.

BIS. (2013). UK Industry Performance Report. Retrieved from http://www.constructingexcellence.org.uk/pdf/KPI_Report_2011.pdf. 
Eagan, J. (1998). Rethinking Construction. London: Stationary Office.

Edge, M., Craig, A., Laing, R., Abbott, L., Hargreaves, A., Scott, J., \& Scott, S. (2002) Overcoming Resistance to Prefabrication and Standardisation in Housing. Aberdeen: Robert Gordon University.

Goodier, C., \& Gibb, A. (2007). Future opportunities for offsite in the UK. Construction Management and Economics, 25(6), 585-595.

Gray, D. E. (2013). Doing research in the real world. Sage.

Health and Safety Executive. (2014). Health and safety in construction sector in Great Britain 2014/15. London: HSE. Retrieved form http://www.hse.gov.uk/statistics/industry/construction.pdf

HM Government. (2014). Construction 2025. London: Stationary Office.

King, A, P., Knight, A, D., \& Griffith, A. (2001). Understanding the dynamics of novation: a contractor's perspective. In: Annual ARCOM Conference, 5-7 September 2001, Salford, UK. Association of Researchers in Construction Management, 1(1), 951-9.

Latham, S. M. (1994). Constructing the team. HM Stationery Office.

$\mathrm{Lu}, \mathrm{N}$. (2009). "The current use of offsite construction techniques in the United States construction industry." Seattle, Washington, 96-96.

Lyons, M. (2014). Mobilising the nation to build the homes our children need. London: Labour Party.

McGraw-Hill (2011). "Prefabrication and modularization: Increasing productivity in the construction industry." Smart Market Report.

McKinsey Global Institute. (2015). The global affordable housing challenge. Retrieved from http://www.mckinsey.com/urbanization/tackling_the_affordable_housing_challenge.

Miles, J. \& Whitehouse, N. (2013). Offsite Housing Review. London: Construction Industry Council.

Nadim, W., \& Goulding, J. S. (2010). Offsite production in the UK: the way forward? A UK construction industry perspective. Construction innovation. 10(2), 181-202

National Audit Office. (2005) Using Modern Methods of Construction to Build Homes more quickly and efficiently. London: Stationary Office

Oppenheim, A, N. (1992). Questionnaire design, interviewing and attitude measurement. London: Pinter Publishers.

Pan, W., Gibb, A. G., \& Dainty, A. R. (2007). Perspectives of UK house builders on the use of offsite modern methods of construction. Construction Management and Economics, 25(2), 183-194.

Stake, R. E. (1980). Seeking sweet water: Case study methods in educational research. New York: American Educational Research Association.

Venables, T., Barlow, J., and Gann, D. (2004). "Manufacturing Excellence-UK Offsite Capacity." Innovation Studies Centre, Imperial College London, 62pp.

World Energy Council, W. E. (2013). "World energy resources." Word Energy Council, London.

Yin, R. (2013). Case study research: Design and methods (1st ed.). Beverly Hills, CA: Sage Publishing. 